\section{POS0095 DEVELOPPING A SCORE TO PREDICT PRECLINICAL INTERSTITIAL LUNG DISEASE IN PATIENTS WITH RHEUMATOID ARTHRITIS - A CROSS-SECTIONAL STUDY FROM THE ESPOIR COHORT}

P. A. Juge ${ }^{1}$, B. Granger ${ }^{2}$, M. P. Debray ${ }^{3}$, E. Ebstein ${ }^{1}$, F. Louis Sidney ${ }^{4}$, J. Kedra ${ }^{2}$, R. Borie ${ }^{5}$, A. Constantin 6 , B. Combe ${ }^{7}$, R. M. Flipo ${ }^{8}$, X. Mariette ${ }^{9}$, O. Vittecoq ${ }^{10}$, A. Saraux ${ }^{11}$, G. Carvajal Alegria ${ }^{11}$, J. Sibilia ${ }^{12}$, F. Berenbaum ${ }^{13}$, C. Kannengiesser ${ }^{14}$, C. Boileau ${ }^{14}$, B. Crestani ${ }^{5}$, B. Fautrel ${ }^{2}$, P. Dieudé1. ${ }^{1}$ Bichat-Claude Bernard Hospital, Rheumatology, Paris, France; ${ }^{2}$ University Hospitals Pitié Salpêtrière - Charles Foix, Rheumatology, Paris, France; ${ }^{3}$ BichatClaude Bernard Hospital, Radiology, Paris, France; ${ }^{4}$ Hospital Pierre ZobdaQuitman, Rheumatology, Fort-de-France, Martinique; ${ }^{5}$ Bichat-Claude Bernard Hospital, Pulmonology, Paris, France; ${ }^{6}$ Hospital Pierre Paul Riquet Toulouse, Rheumatology, Toulouse, France; ${ }^{7}$ Chu Montpellier, Rheumatology, Montpellier, France; ${ }^{8} \mathrm{Chu}$ De Lille, Rheumatology, Lille, France; ${ }^{9} \mathrm{CHU}$ du Kremlin-Bicètre, Rheumatology, Le Kremlin-Bicêtre, France; ${ }^{10} \mathrm{CHU}$ Hôpitaux de Rouen, Rheumatology, Rouen, France; ${ }^{11}$ Hospital De Carhaix, Rheumatology, CarhaixPlouguer, France; ${ }^{12}$ Chu Strasbourg, Rheumatology, Strasbourg, France;

${ }^{13}$ Hospital Saint-Antoine Ap-Hp, Rheumatology, Paris, France; ${ }^{14}$ Bichat-Claude Bernard Hospital, Genetic, Paris, France

Background: Interstitial lung disease (ILD) is an extra-articular manifestation of rheumatoid arthritis (RA) detected in $20 \%$ to $60 \%$ of patients with RA on high-resolution computed-tomography (HRCT) chest scan and is clinically significant in near $10 \%$. Despite a high morbi-mortality rate, a definite strategy for preclinical ILD screening in patients with RA remains to be determined. To date, several factors have been reported to increase the risk of RA-ILD occurrence (i.e. older age at RA onset, ACPA positivity, male sex, RA disease activity, the MUC5B rs35705950 promoter variant...). However, none of these risk factors has been validated in a prospective cohort of patients with RA. The ESPOIR prospective cohort includes patients aged 18 to 70 years with recent arthritis (less than 6 months) and a definite or probable diagnosis of RA.

Objectives: To identify in the ESPOIR cohort factors associated with ILD after at least 10 years of RA duration in order to develop a predictive score to identify patients with preclinical RA-ILD.

Methods: An ILD detection by chest HRCT scan was systematically offered to every patient with definite RA after at least 10 years-follow-up. Chest HRCT scans were centrally reviewed by an experienced radiologist. Potential predictors of ILD were prospectively collected from baseline to the date of the HRCT scan, and all included patients were genotyped for MUC5B rs35705950. To take into account repeated measures, trajectories were determined for disease activity, $\mathrm{C}$ reactive protein, smoking, treatment exposure (i.e. prednisone, methotrexate [MTX] and biological disease modifying anti-rheumatic drugs [bDMARDs]). A logistic model was used to identify independent predictors for the occurrence of ILD on HRCT scans. Confidence intervals were estimated using sampling methods. A predictive score for preclinical ILD occurrence was developed based on the identified predictors.

Results: 163 RA patients according to 2010 ACR/EULAR classification criteria, none of whom had pulmonary symptoms, were investigated with a chest HRCT scan (128 women $(78.5 \%)$, mean RA duration $13.7 \pm 1.1$ years, age at inclusion $47.6 \mathrm{y} / \mathrm{o} \pm 10.4$, mean disease activity score [DAS]-28 during follow up was $3.1 \pm 1.0)$. ILD was detected in 31 patients $(19.0 \%)$. The MUC5B rs35705950 minor allele frequency (MAF) was $22.2 \%$ and $10.0 \%$ in the RA-ILD and RA-noILD populations, respectively (OR univariate $=2.6 \mathrm{Cl}_{95 \%}$ [1.2-5.5], $\mathrm{P}=0.01$ ). After logistic regression, independent predictors for preclinical RA-ILD were male sex $\left(\mathrm{OR}=3.9 \mathrm{Cl}_{95 \%}[1.4-11.4]\right)$, older age at $\mathrm{RA}$ onset $\left(\mathrm{OR}=1.1\right.$ per year $\left.\mathrm{Cl}_{95 \%}[1.0-1.2]\right)$, mean DAS-28 score during the follow-up (OR=2.0 Cl ${ }_{95 \%}$ [1.2-3.4]) and $M U C 5 B$ rs35705950 T risk allele $\left(\mathrm{OR}=3.7 \mathrm{Cl}_{95 \%}[1.4-10.4]\right)$ (Figure 1). No influence of the use of RA-related drugs (prednisone, MTX or bDMARDs) was identified as risk factor. The logistic model could predict preclinical ILD occurrence after 13 years of RA duration with an $\mathrm{AUC}=0.82 \mathrm{Cl}{ }_{5 \%}$ (0.72-0.91). A predictive score for preclinical RA-ILD based on the 4 identified predictive risk factors was developed (Sensitivity $80 \%$, Specificity $56 \%$ ).

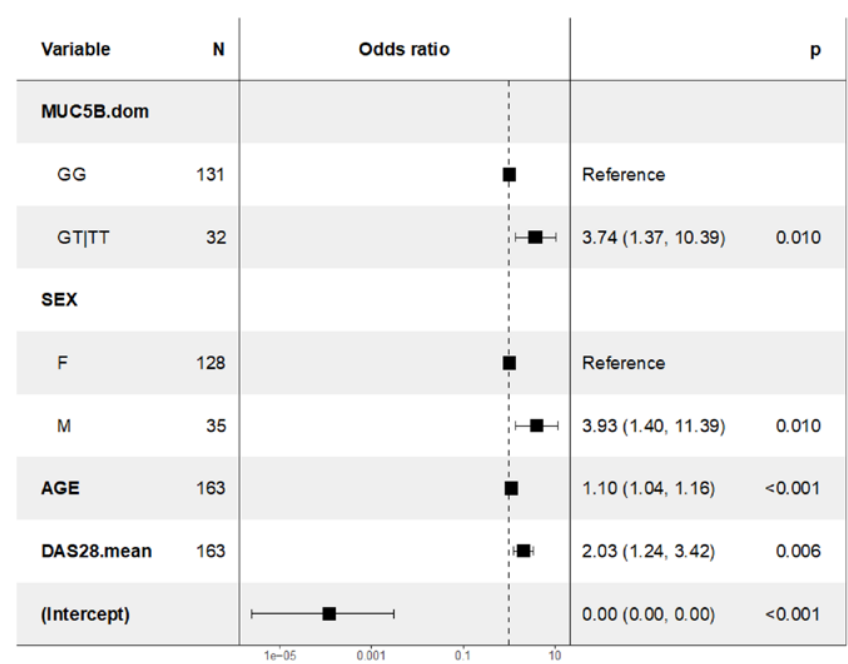

Figure 1. Factors independently associated with preclinical ILD after 13 years of RA duration

Conclusion: In this cross-sectional study of the prospective ESPOIR cohort, we identified clinical and genetic predictors for ILD after 13 years of RA duration. We developed a predictive score that could improve risk stratification for preclinical RA-ILD and help physicians identify patients with RA in whom a HRCT scan should be performed. Disclosure of Interests: Pierre-Antoine Juge Consultant of: BMS, Benjamin Granger: None declared, Marie-Pierre Debray: None declared, Esther Ebstein: None declared, Fabienne Louis Sidney: None declared, Joanna KEDRA: None declared Raphael Borie: None declared, Arnaud Constantin Consultant of: Bristol-Meyers Squibb, Chugai, Roche, Abbvie, MSD, Pfizer, and UCB, Bernard Combe Consultant of: Abbvie, Bristol-Meyers Squibb, Lilly, MSD, Janssen, Pfizer, Roche, Chigai, and Sanofi, Grant/research support from: Abbvie, Bristol-Meyers Squibb, Lilly, MSD, Janssen, Pfizer, Roche, Chugai, and Sanofi, René-Marc Flipo Consultant of: Bristol-Meyers Squibb, Roche, Chugai, Abbvie, and Pfizer, Grant/research support from: Roche, Chugai, Abbvie, and Pfizer, Xavier Mariette Consultant of: Bristol-Meyers Squibb, GSK, Janssen, Pfizer, and UCB, Olivier VITTECOQ Consultant of: Bristol Myers Squibb, Roche, Chugai, MSD, Novartis, Pfizer, Abbvie, and Lilly, Alain Saraux Consultant of: Roche, Chugai, and Bristol-Meyers Squibb, Grant/research support from: Roche, Chugai, and Bristol-Meyers Squibb, Guillermo CARVAJAL ALEGRIA: None declared, Jean Sibilia Consultant of: Roche, Chugai, Bristol-Meyers Squibb, UCB, GSK, LFB, Actelion, Pfizer, MSD, Novartis, Amgen, Hospira, AbbVie, Sandoz, Gilead, Lilly, Sanofi, Janssen, and Mylan, Francis Berenbaum Consultant of: Boehringer, Bone Therapeutics, Expanscience, Galapagos, Gilead, GSK, Elli Lilly, Merck Sereno, MSD, Nordic, Novartis, Pfizer, Regulaxis, Roche, Sandoz, Sanofi, Servier, UCB, Peptinov, TRB Chemedica, 4P Pharma, Caroline Kannengiesser: None declared, Catherine Boileau: None declared, Bruno Crestani Consultant of: Boehringer Ingelheim, Roche, Sanofi, Apellis, Astra-Zeneca, Grant/research support from: Medlmmune, Boehringer Ingelheim, Bruno Fautrel Consultant of: AbbVie, Biogen, BMS, Celgene, Janssen, Lilly, Medac, MSD, NORDIC Pharma, Novartis, Pfizer, Roche, Sanofi-Aventis, SOBI, UCB, Grant/research support from: AbbVie, MSD, Pfizer, Philippe Dieudé: None declared

DOI: 10.1136/annrheumdis-2021-eular.2817

\section{\begin{tabular}{|l|l}
\hline POS0096 SPLENIC METABOLIC UPTAKE IN FDG-PET/CT \\
\hline
\end{tabular} PREDICTS RISK OF FUTURE CARDIOVASCULAR THROMBOSIS EVENTS IN PATIENTS WITH RHEUMATOID ARTHRITIS}

S. J. Lee ${ }^{1}$, C. M. Hong ${ }^{2}$, Y. M. Kang ${ }^{1} .^{1}$ School of Medicine, Kyungpook National University, Internal Medicine, Daegu, Korea, Rep. of (South Korea); ${ }^{2}$ School of 